A strong argument against tarring open-access publication with the vanity-press brush is that there is no reason that monographs published under legitimate open-access models cannot undergo peer review and editing processes as rigorous as any undergone by traditionally published monographs. Quality peer review and editing are not, after all, functions of paper and ink.

Another counter to vanity-press accusations is that, with very few exceptions, the cost of publishing a scholarly monograph has always been underwritten in one way or another. In the past, the publication costs for any given printed scholarly monograph were very likely underwritten by a university press campus subsidy. Any argument that such traditional models for subsidizing the publication of scholarly monographs occupy some higher moral ground than do the emerging models of open-access scholarly publishing is entirely specious.

If, in the end, the forces of academic conservatism kill the open-access scholarly monograph by refusing to hire or reward emerging scholars who publish in this way, an unintended consequence will be the death of the scholarly monograph. Certainly, it is foolish to think that aborting the open-access scholarly monograph will save its print-format forerunner. The reality is that scholarly publishers, including non-profit university presses, cannot afford to perpetually lose money printing books that academic libraries cannot afford to buy. Open access offers an alternative to a market in collapse. Without such an alternative, production will inevitably come to a halt, and the scholarly monograph will become as much a relic of the past as the scroll and the illuminated manuscript.

\section{Giving Credit Where Credit Is Due}

\section{Philip G. Altbach}

Philip G. Altbach is research professor and founding director of the Center for International Higher Education at Boston College. E-mail: altbach@bc.edu. A different version of this article appeared in The Conversation.

I $\mathrm{t}$ was striking that the headline on the first page of China 1 Daily, on October 6, 2015, was "China wins first Nobel prize in medicine." Actually, Dr. Tu Youyou of the China Academy of Traditional Chinese Medicine won the prize, not the country. That same day, on page 4 of the New York Times, the headline read " 3 share Nobel for work on treat- ment of devastating parasitic diseases"-the article noting, almost in passing, where the three winners came from-: the United States, China, and Japan. It is one thing to celebrate the number of Olympic medals won by athletes from a particular country-after all, the medals are awarded with flags flying and national anthems blaring-but scientific achievement is quite something else. Another aspect of the irrationality of contemporary science is the explosion in the number of coauthors of articles in many scientific journals. Nobel credits and irrational co-authorship are illustrative of two sides of the same coin: systems of scientific credit have run amok.

\section{What is the Nobel Committee Awarding, After All?}

Nobel prizes are awarded for specific and notable achievements and, by implication, a lifetime of scientific work. The credit accrues to the researcher or sometimes several colleagues or scientists working independently on a similar topic. The country where the research was done has little, if anything, to do with the achievement. Indeed, as is often the case, the researcher may be from one place, and is working in another. The American who was co-winner in medicine, Dr. William Campbell, for example, was born in Ireland, received his bachelor's degree in Ireland and his doctorate at the University of Wisconsin. He did his prize-winning work finding treatments for parasite infections while at Merck, an American pharmaceutical company. Indeed, many Nobelists, especially Americans, were born and received part or all of their education in other countries. And many are no longer working at the universities where they did their pioneering work.

Thus, Nobel prizes are the work of individuals or teams. Increasingly, science is carried out by groups of researchers, often affiliated to a particular laboratory. The Nobel committee has yet to recognize the implications of the fully collaborative and international realities of contemporary science-they do not award prizes to groups and, indeed, limit the number of scientists who can receive a specific prize to three.

\section{Credits Run Amok}

If the Nobel authorities set hard limits for allocating credit, academic science may have gone off the deep end in the other direction. An article was recently published in Physical Review Letters, a respected journal, with 5,I54 authors. Another Physical Review Letters paper from 2012 has close to 3,000 authors-2I of whom were deceased by the time the article was published.

One of the authors of the latest paper, Dr. Aad, who is listed first, will receive a huge number of citations, no doubt boosting his reputation and increasing the citation rate for his university. The topic was the Higgs Boson, and 
the article involved collaboration among scientists in many countries. This seems to be a world record for co-authors, although there are an increasing number of published articles with I,O०० or more coauthors.

While it is certainly true that science has become more collaborative, there seems to be little justification for listing such a large number of authors. Could they have all contributed substantively? Just as there was no rationale for listing as first author the senior scientist in a laboratory, even if he or she had done little or no work on the specific article, as was common and remains a practice in some laboratories and departments, it seems at least some of these many hundreds of coauthors are getting a courtesy listing. It is not appropriate to provide authorship credit to people who have had a remote relationship to the writing and preparation of the actual article.

This issue is important for a number of reasons, among them that citation counts are used for university rankings as well as for national policymaking in some countries and often for the evaluations of individual professors when promotions or salary increases hang in the balance.

\section{While it is certainly true that science has become more collaborative, there seems to be little justification for listing such a large number of authors.}

\section{What Does It All Mean?}

Globalization, academic competition, misplaced nationalism, the obsession with rankings, ever increasing demands for accountability by governments, and significant changes in how science is carried out all contribute to our contemporary "credit problem." Although the examples cited here may seem to border on trivial, they are actually important. Scientific productivity is increasingly an international phenomenon, with top researchers educated in one country, working in another, and frequently developing and sharing research with colleagues around the world.

Thus, science is global and it is increasingly irrelevant to credit Nobel research to a country or university. Yet, support for basic research is dwindling everywhere-and it is on the basis of basic research that Nobel-level discoveries are made. Countries that provide funding and autonomy for basic research will inevitably scoop up the best scholars and scientists.

At the same time, the scientific community itself must be reasonable about distributing authorship credit for aca- demic articles. These articles, especially those published in the top refereed print and electronic journals, remain the gold standard of science and are a central means of knowledge and dissemination. The number of authors should be limited to those who have actually been involved in the writing of the article, even if a much wider community contributed insights or data to it. Others can be mentioned in relevant credits or references.

As in so many aspects of contemporary science and higher education, we are in the midst of an "academic revolution" in scientific recognition and research support and evaluation. A rational approach is needed to restore sanity to a system that is increasingly out of control, from the Nobels to articles "authored" by thousands.

\section{Higher Education Research Goes Global}

\section{HANS DE WIT}

Hans de Wit is professor and director of the Center for International Higher Education at Boston College, US. E-mail: dewitj@bc.edu.

Tntil recently the study of higher education and its international dimensions was the field of a small group of research centers and scholars, primarily in the developed world, and even there, funding and resources were scarce. There are two new initiatives, though, which indicate a more positive and global development of research in international higher education. These initiatives can be seen as a product of the "Shanghai Statement: The Future of Higher Education: The Need for Research and Training for the Higher Education Enterprise" in 20I3. Reflecting the thinking of 33 research and policy professionals concerning the future development of the field of higher education research, policy, and training, the statement noted: "This developing field is so far limited to a fairly small group of countries." The statement made an appeal for more research and the development of research centers at universities around the world, for doctoral studies in international higher education, and adequate funding.

\section{The Centre for Global Higher education}

The official launch of the ESRC/HEFCE Centre for Global Higher Education, or CGHE, took place on 2-3 February 2016 in London. CGHE is the largest research center in the world specifically focused on higher education and its future development. It has more than $£ 6$ million (US\$8.7 